Egyptian

Orthodontic Journal

\title{
SHEAR BOND STRENGTH OF SOME ORTHODONTIC ADHESIVES UNDER WET CONDITION; AN IN VITRO STUDY
}

\author{
Tamer A Ramadan ${ }^{1}$, Abbadi A ElKadi \\ Waleed EL Sayed Refaat ${ }^{3}$
}

ABSTRACT:

This study was designed to evaluate the shear bond strength of orthodontic brackets bonded to teeth under salivary contamination using three bonding systems; composite with self etching primer, composite with moisture insensitive primer and Assure hydrophilic bonding system. The adhesive remaining index scores were inspected and recorded for each group. Freshly extracted 45 human sound premolars were used in this study. They were randomly divided into three equal groups; each group was assigned with a bonding system. Debonding was done using a universal testing machine. The debonding forces were recorded and statistically analyzed. The results showed that all the three used bonding systems were in the clinically accepted range of the shear bond strength. Moisture insensitive primer group recorded the highest shear bond strength values followed by the self etching primer group; While Assure hydrophilic bonding system recorded the lowest shear bond strength values.

For adhesive remaining index scores, the Assure group recorded the least remaining adhesive on the teeth followed by moisture insensitive primer group. While the self etch group recorded the highest remaining index scores.

1- Postgraduate student, Orthodontic Dept, Suez Canal University.

2- Professor of Orthodontics, Suez Canal University.

3- Lecturer of Orthodontics, Suez Canal University. 
Egyptian

Orthodontic Journal

\section{INTRODUCTION}

Direct bonding of orthodontic appliances to enamel with composite resin and acid-etching technique was first performed by Newman in 1965 and it is now widely accepted and used by most of orthodontists. Conventional resin composites require the use of three different agents (enamel conditioner, primer, and adhesive resin) to bond orthodontic brackets to enamel.

Evaluations of the degree of curing of chemically cured and light cured adhesive were studied. Using of spectroscopic analysis to evaluate the visible light transmitted through the stainless steel brackets. The conclusion was the degree of curing of indirect irradiation method was significantly higher than that of direct irradiation method ${ }^{(1-3) \text {. }}$

Studying the shear bond strength of different light activated composite types were carried out. After thirty minutes the shear bond strength was assessed. The study revealed that, under the same conditions, the shear bond strength of the Tansbond XT showed higher values than Orthoprimer. ${ }^{(4-6)}$

Comparing the effects on shear bond strength of removing excess adhesive around the bracket base has been investigated.The investigation carried out at 2 time periods: (1) immediately after placing the bracket on the tooth, and (2) after subjecting the adhesive to 5 seconds of light curing to initially secure the bracket in its proper position. Their results showed that removing excess adhesive after an initial 5 seconds of light cure significantly decreased the shear bond strength and they concluded that excess adhesive should be removed around the brackets while the adhesive is in a relatively soft stage before being light cured. ${ }^{(7-9)}$

Comparing bond strengths of newer bonding systems with either bioactive components or self-etching primers with a conventional bonding system has been analyzed. The bond strength was tested for all groups and the results were statistically analyzed. The results showed that Aegis Ortho, Clearfil Protect Bond, Clearfil S3 Bond, and I Bond produced lower bond strengths than did Transbond XT, with I Bond's strength lower than what might be acceptable for clinical usefulness. ${ }^{(10-12)}$ 
Egyptian

Orthodontic Journal

Evaluation of water and saliva contamination on shear bond strength of brackets bonded with a moisture-tolerant light cure system has been studied. The adhesive remnant on the teeth was quantified with the use of image analyzing equipment. The results indicated that without contamination, bond strengths for the four procedures were similar, bond strength and adhesive remaining for. They concluded that TSEP/Transbond PLUS, TMIP/Transbond PLUS, and TSEP/Transbond XT showed greater tolerance to wet conditions than was shown by TMIP/Transbond XT. ${ }^{(13,14)}$

Assessment of blood and saliva contamination on the shear bond strength of four orthodontic adhesives (Transbond XT primer, Transbond Plus self-etch primer [3M Unitek], Assure hydrophilic primer, and Smart Bond cyanoacrylate was studied. They concluded that under blood-contaminated conditions, both Assure hydrophilic primer with Transbond XT adhesive and Smart Bond have significantly higher bond strength values than the conventional primer and adhesive combination ${ }^{(15,16)}$

Using the ARI system the researches were performed to determine 3 dimensionally the amount of adhesive remaining on teeth after debonding orthodontic brackets. Three bonding materials were used in this study Light Bond, Transbond and Fuji Ortho adhesive. Shear bond strength test was applied to the three groups as well as adhesive remaining index assessment. They found that Fuji Ortho had the lowest bond strength than Transbond and Light Bond, also it has significantly greater incidences of enamel-adhesive failure. ${ }^{(17,18)}$

\section{Aim of the work:}

The aim of this study was to investigate the shear bond strength of different Orthodontic adhesive systems under wet condition and to assess the amount of adhesive remained on specimen after debonding.

\section{MATERIALS AND METHODS}

Forty five extracted premolars with straight wire premolar brackets were bonded using three types of adhesives. Each tooth was fixed in a self-cure acrylic block such that the roots were completely embedded in the acrylic up to the cement enamel junction. 
Forty five straight wire premolar brackets $(0.22 \text { Roth prescription })^{(*)}$ were used in this study.

The following bonding systems were used in this study

1- Self etching primer ${ }^{(* *)}$ in conjunction with light cured composite resin

2- Moisture insensitive primer ${ }^{(* * *)}$ in conjunction with light cured composite resin.

\section{3- Hydrophilic resin system (Assure) ${ }^{(* * *)}$}

4- Glandosane Artificial saliva ${ }^{(* * * *)}$

Each tooth was cleaned and polished with non-fluoridated, oil-free, pumice paste applied with a rubber prophylactic cup on a slow-speed hand piece for 5 seconds, rinsed with water, and dried with an oil- and moisture-free air spray for 30 seconds

After priming, the specimens were immersed in the artificial saliva.

The blocks were randomly divided into three groups fifteen teeth each coded (I) with SEP, (II) with MIP, and (III) with Assure bonding system.

The debonding was done using computerized universal testing machine in order to evaluate the shear bond strength for each group.

\section{RESULTS}

Table (1): Descriptive statistics and test of significance of shear bond strength and $\mathrm{P}$ values of all groups

\begin{tabular}{|l|c|c|c|c|c|c|}
\hline \multicolumn{1}{|c|}{ Group } & Mean & S.D. & Minimum & Maximum & dt & P \\
\hline Group I & 15.086 & 1.232 & 12.65 & 16.98 & b & I \& II $=0.003$ \\
\hline Group II & 16.638 & 1.329 & 14.66 & 19.31 & a & II \& III $=0.05$ \\
\hline Group III & 13.164 & 1.146 & 11.24 & 15.21 & c & III \& I $=0.05$ \\
\hline
\end{tabular}

S.D. $=$ Standard deviation

$\mathrm{dt}=$ Duncan's Multiple Range Test for the effect of group.

\footnotetext{
* Ortho Organizers, Inc. USA.

** Transbond plus, 3M Unitek.

*** MIP, 3M Unitek.

**** Reliance Orthodontics, Itasca, III.

****** (Glandosane synthetic saliva, Fresenius Medical Care Deutscland GMBH, Wendel, Germany).
} 
Egyptian

Orthodontic Journal

The unit of measurement was MPa (mega pascal)

Means with the same letter within each column are not significantly different at $\mathrm{p} \leq 0.05$.

From table (1) it could be showed that there were significant differences between all groups.

The comparison between group I $(15.086+1.232)$ and group II $(16.638+1.329)$ showed significant difference where t (3.316) at $\mathrm{p}<0.05$

The difference of means between Group II $(16.638 \pm 1.329)$ and Group III (13.164 \pm 1.146$)$ was significant $t 7.666$, at $p<0.05$

On the same way the comparison of mean shear bond strength between Group I (15.086 \pm 1.232$)$ and Group III $(13.164 \pm 1.146)$, showed significant differenceas well , $\mathrm{t}(4.423)$ at $\mathrm{p}<0.05$

An assessment of the amount of remaining adhesive was done using the score that was developed by Årtunand Bergland ${ }^{(8)}$. This step was done by inspection under a magnifying lens according to Bisharaet al., ${ }^{(9)}$ and Kimuraetal., ${ }^{(10)}$.

The findings were collected in table (2)

Table (2): Descriptive statistics and test of significance of adhesive remaining index scores of all group ( $\mathrm{dt}=$ Duncan test)

\begin{tabular}{|l|c|c|c|c|c|}
\hline Group & Mean & S.D. & Minimum & Maximum & dt \\
\hline Group I & 2.867 & 0.352 & 2 & 3 & $\mathrm{a}$ \\
\hline Group II & 2.600 & 0.828 & 0 & 3 & $\mathrm{a}$ \\
\hline Group III & 1.467 & 1.187 & 0 & 3 & $\mathrm{~b}$ \\
\hline
\end{tabular}

Means with the same letter within each column are not significantly different at $\mathrm{p} \leq 0.05$.

From table (2) it could be seen that there was no significant difference of prevalence of adhesive remnant between Group I and Group II $\mathrm{p}<0.05$.

While there was significant difference regarding the amount of adhesive remnant between Group I and Group III, p>0.003. 
Egyptian

Orthodontic Journal

Also there was significant difference between Group II and Group III regarding the amount of adhesive remnant $\mathrm{p}<0.05$.

\section{DISCUSSION}

The acid etch bonding technique is considered as a primary mean of direct attachment of the orthodontic brackets to teeth that improved the clinical practice of orthodontics

Completely dry enamel surface was recommended in the bonding procedure during curing of the adhesive. As complete dryness is difficult to be obtained and preserved during the whole period of bonding; the moisture insensitive primers was developed. This type of primers claims to be not affected by moisture contamination.

A new group of hydrophilic adhesive systems was introduced to practice, those products claimed to be not affected by water or saliva contamination. Accordingly, the present study was designed to evaluate the effect of saliva contamination on shear bond strength of orthodontic brackets bonded to teeth using three different bonding systems

Extracted human premolars were used in this study because they are the most teeth to be extracted during orthodontic treatment.

The results of this study showed that all shear bond strength values were in the clinically accepted range as testified by Reynolds ${ }^{(11)}$ who suggested that the adequate shear bond strength for clinical use should range from 6 to $8 \mathrm{MPa}$. The mean bond strength of Group I (self etching primer group) was $15.086 \mathrm{MPa} \pm 1.232$ which is suitable to be used in bonding orthodontic attachments and range in the clinically accepted limit. The results were in agreement with Assar ${ }^{(12)}$ who tested the self etching primer under wet condition and suggested that it could provide a clinically accepted values. Also the results were in agreement with Bishara et al., ${ }^{(9)}$ who stated that self etching primer provide lower but clinically accepted shear bond strength.

By comparing both groups (I and II) the results showed that moisture insensitive primer produces significantly higher shear bond strength values than self etching primer however both are in the clinically 
accepted range. This is in agreement with Ciola et al., ${ }^{(13)}$ who tested both materials under wet condition and founded that moisture insensitive primer under wet condition showed higher mean bond strength than self etching primer. This was supported by Rajagopal et al., ${ }^{(14)}$ who compared shear bond strength of moisture insensitive primer and self etching primer under wet condition and their results showed that moisture insensitive primer had the highest results followed by self etching primer.

For Group III (Assure hydrophilic bonding system) the mean shear bond strength was $13.164 \mathrm{MPa} \pm 1.146$ which is lower than that of group I and II but still clinically accepted. This is in agreement with Schaneveldt and Foley ${ }^{(15)}$ who evaluated the shear bond of Assure bonding system under wet condition and stated that it provides adequate bond strength. This was supported by Websteret al., ${ }^{(16)}$ who found Assure bonding system tend to have accepted shear bond strength that improves with reapplication of the primer. The research of Nemeth et al., ${ }^{(17)}$ also was in agreement with the results of this study as they compared the shear bond strength of conventional Transbond XT and Assure bonding system under wet condition and suggested that Assure bonding system can successfully be used under moist conditions.

The range of ARI scores demonstrated that Group III (Assure) had the lowest mean ARI score $1.467 \pm 1.187$ followed by Group II that (Transbond XT with moisture insensitive primer) showed the next lowest mean ARI $2.6 \pm 0.828$. This may be due to the inherent hydrophilic properties of the resin and the possibility of dilution of the primer with saliva, especially since the hydrophilic primer is not light cured after its application. Group I (self etching primer) showed the highest mean ARI. The difference was not significant between groups I and II. While there was significant difference during comparing Group III to either Group I or Group II. These results are in agreement with Bishara et al., ${ }^{(9)}$ who stated that the use of self-etch primer results in higher frequency of ARI scores, which indicated more composite remains on the teeth. These are in agreement also with Zeppieri et al., ${ }^{(18)}$ who found no significant difference between Self etching primer and Moisture insensitive primer under wet condition. This was in agreement also with Schaneveldt and Foley ${ }^{(15)}$ who found that there is a significant difference in the ARI scores between Assure and MIP. 
Egyptian

Orthodontic Journal

\section{REFERENCES}

1- Eliades T, Eliades G, Brantley WA and Johnston WM. Polymerization efficiency of chemically cured and visible light-cured orthodontic adhesives: Degree of cure. Am J Orthod Dentofac Orthop. 1995; (108):294-301.

2- Vilar RV, Souza NF, Cal-Neto JP, Galvão M, Sampaio-Filho H, and Mendes A M. Shear bond strength of brackets bonded with two light-curing orthodontic adhesives. J Adhes Dent. 2009;(11):259-262.

3- Bishara SE, Von Wald L, Olsen ME, and Laffoon JF. Comparisons of two approaches for removing excess adhesive during the bonding procedure. Angle Orthodontist. 2000;(70): 149-153.

4- Minick GT, Oesterle LJ, Newman SM, and Shellhart WC. Bracket bond strengths of new adhesive systems. Am J Orthod Dentofacial Orthop 2009; (135):771-776.

5- Vicente A, Mena A, Ortiz AJ, and Bravo LA. Water and Saliva Contamination Effect on Shear Bond Strength of Brackets Bonded with a Moisture-Tolerant Light Cure System. Angle Orthodontist. 2009;(79):127-132.

6- Öztoprak MO, Isik F, Sayınsu K, Arun T, and Aydemira B. Effect of blood and saliva contamination on shear bond strength of brackets bonded with 4 adhesives. Am J Orthod Dentofacial Orthop. 2007;(131):238-242.

7- Lee YK, and Lim YK. Three-dimensional quantification of adhesive remnants on teeth after debonding. Am J Orthod Dentofacial Orthop. 2008;(134):556-562.

8- Årtun J and Bergland S. Clinical trials with crystal growth conditioning as an alternative to acid-etch enamel pretreatment. Am J Orthod. 1984; (85): 333-340.

9- Bishara SE, Von Wald L, Laffoon FJ, and Warren JJ. Effect of a self-etch primer adhesive on the shear bond strength of orthodontic brackets. Am J Orthod Dentofacial Orthop. 2001; (119):621-625. 
10- Kimura T, Dunn WJ and Taloumis JL. Effect of fluoride varnish on the in vitro bond strength of orthodontic brackets using a self etching primer system. Am J Orthod Dentofacial Orthop. 2004;(125):351-357.

11- Reynolds I.A review of direct orthodontic bonding. Br J Orthod. 1975; (2):171-178. Quoted from Brad burn G and Pender N. An in vitro study of the bond strength of two composites used in the direct bonding brackets to molars. Am J Orthod Detnofac Orthop. 1992;(102):418-426.

12- Assar N.A. Evaluation of shear bond strength of different orthodontic adhesives and self - etch primer under different conditions. Master thesis, Suez Canal University 2007.

13- Ciola EN, Picco AM, Sois AM, Lucena MH, Alonso V, Valvo M, García L, and Geazzi A. In vivo bracket bond strength using two adhesive systems applied under wet and dry conditions. Acta Odontol Latinoam 2006;(19):37-43.

14- Rajagopal R, Padmanabhan S, and Gnanamani J.A Comparison of shear bond strength and debonding characteristics of conventional, moisture-insensitive, and self-etching primers in vitro. Angle Orthodontist. 2004;(74): 264-268.

15- Schaneveldt S, and Foley TF. Bond strength comparison of moisture insensitive primers. Am J Orthod Dentofacial Orthop. 2002;(122):267-273.

16- Webster MJ, Nanda RS, Duncanson MG, Khajotia S, and Sinha PK. The effect of saliva on shear bond strengths of hydrophilic bonding systems. Am J Orthod Dentofacial Orthop. 2001;(119):54-58.

17- Nemeth BR, Wiltshire WA, and Lavelle CL. Shear/peel bond strength of orthodontic attachments to moist and dry enamel. Am J Orthod Dentofacial Orthop. 2006;(129):396-401 .

18- Zeppieri IL, Chung CH, and Mante FK. Effect of saliva on shear bond strength of an orthodontic adhesive used with moisture-insensitive and self-etching primers. Am J Orthod Dentofacial Orthop. 2003;(124):414-419. 